\title{
The Impact of Syrian Refugees on a Receiving State's Public Expenditure: Evidence from Jordan
}

\author{
Wa'ed Alshoubaki \\ Department of Public Administration \\ The University of Jordan \\ Michael Harris \\ Department of Public Administration \\ Tennessee State University
}

\begin{abstract}
The massive influx of 1.2 million Syrian refugees in Jordan has increased the demand for public services. The study aims to investigate the impact of Syrian refugees on Jordanian public expenditure, and is based on regional focus. It assesses the structural impact of Syrian refugees on total public expenditure, including current public and capital expenditure, and investigates their impact on the public health and education sectors. Regression analysis has been utilized to determine how the influx of Syrian refugees has affected Jordanian public spending. The results suggest both that total public expenditure has increased due to the influx of Syrian refugees and that current public expenditure has increased at the expense of capital spending. Moreover, the results suggest that the presence of Syrian refugees positively affects total health care expenditure but negatively affects capital expenditure, and that public education expenditure has increased due to their presence.
\end{abstract}

Keywords: Public finance, public expenditure, receiving state, refugees

\section{Introduction}

The number of refugees around the world was 59.5 million at the end of 2014 (UNHCR, 2015). Syrians refugees have exceeded Afghanis refugees the world's largest refugee population, and the Hashemite Kingdom of Jordan, as a neighboring country, has received an alarming number, forcing it to confront the enormous political, economic, social and environmental challenges that accompany this humanitarian catastrophe. In essence, there are both opportunities and pitfalls: such a massive inflow of refugees could spur infrastructural funding and ultimately transform Jordan's landscape; however, it could also overburden public services and infrastructure, including hospitals, schools, water consumption, and the real estate and the labor markets. According to Jordan's Ministry of Planning and International Cooperation (2015), the macroeconomic effect of the presence of Syrian refugees and the extra demand on public spending have led to the withdrawal of Jordan's developmental goals, and has shifted the Kingdom's focus onto providing humanitarian assistance to refugees and tackling the political ramifications of civil wars in neighboring Syria and Iraq.

Jordan's government bears additional costs associated with the influx of Syrian refugees as it provides such additional services as running and securing camps and other areas where refugees congregate (Nasser \& Symansky, 2014). Moreover, it is obligated to extend these services as the refugee population continues to grow (Nasser \& Symansky, 2014). The sudden increase in Jordan's population has overburdened its government due to the unavoidable additional costs of subsidized goods for poor households including bread, water, electricity, and gas for poor families (Nasser \& Symansky, 2014). According to Nasser and Symansky (2014), Syrian refugees incur direct costs that include actual and projected expenditures in the public budget due to an increase demand for state-subsidized services. Furthermore, Syrian refugees cause indirect costs to the Kingdom by depleting resources and hindering the quality of public services due to the increasingly unmanageable demand. Thus, Jordan is experiencing multi-layered social and economic costs that are also affecting the overall quality of life for its own citizens. The following analysis contributes to the empirical analysis of refugees' studies and public finance to assess the repercussions of sheltering of refugees in the form of social and political crisis on receiving state's public expenditures. We seek to answer the following questions: (1) how has the influx of Syrian refugees affected Jordanian public expenditure and capacity to provide public services? 
And (2) What areas of Jordanian government expenditure and social services have been affected the most by the influx of Syrian refugees? In order to address these questions, we will first consider public finance literature to assess the fiscal impact of receiving refugees on receiving state. Second, statistical models have been developed to predict the impact of Syrian refugees' presence in Jordan as a receiving state as a measure of the burden of refugees' existence in an already vulnerable state.

\section{Literature Review}

\section{Theoretical analysis}

Public spending changes according to political, social, economic and naturally-occurring (environmental, climate) drivers. Governments are exposed to unpredictable and uncontrollable conditions that cause policy makers to increase spending to address unforeseen issues and which ultimately change overall spending patterns to adapt to changed conditions. Increased public expenditure is generally associated with economic development and long term population growth. However, other considerations may cause public spending to increase such as natural disasters or an influx of refugees or internally displaced people due to political conflict or climate-related conditions.

From a public finance perspective, sudden changes in public expenditures have not been examined in relation to short-run, unanticipated population growth coupled with the political reasons for increasing government services in response to growing public demand. Peters (1995) termed one reason for increasing the size of government the "Pogo phenomenon" because, from a political view, a "government grows because citizens demand more services from it" (p. 11). The surge of Syrian refugees into Jordan caused increased demand on already overstretched public services. At the same time, Jordanian citizens were increasingly resentful due to the heightened pressure on public services and the deterioration of the quality of public services. The Jordanian government is obligated simultaneously to assist refugees and to mitigate their negative impact on host communities in order to offset potential social unrest due to substandard economic conditions. In particular, Jordanians have less confidence in their government's ability to respond effectively to the refugee crisis (Francis, 2015). This study will discuss these challenges in more detail.

A further review of the public finance literature shows emphasizes the tools it has for assessing the connection between sudden changes in government and total public expenditures. For example, Peters (1995) has used public spending as a main factor for measuring governmental size in order to examine the changes in governmental responsibilities. He asserted that the public expenditure variable is extensively employed to measure the size of government and to determine the most notable government activities.

In the same vein, Wagner (1883) made a connection between the growth of public expenditure and participatory state activities by arguing that there are multiple roots for public expenditure growth, including social progress, economic growth, increased real income, growth in population and urbanization, and technological development. He attributed the remarkable increase in public expenditure to the extension of state activities, internal security, growth in national defense, urban and rural development, price increases, and population boom (Peters, 1995; Wagner, 1883). Specifically, he considered population changes an essential factor because changes in the rate of population growth cause changes in age distribution, and which ultimately has an effect on expenditures in specific public services (Musgrave \& Musgrave, 1989). For instance, an increase in the number of children leads to an increased demand for educational institutions or growth in the number of elderly people will put increasing pressure on government to provide adequate health care services. In both instances, public expenditures face burdensome demands, but these different trends affect where expenditures are allocated.

Okafor and Eiya (2011) studied government expenditure growth in Nigeria and the responsible factors. They examined the major determinants of public expenditure, including inflation, public debt, tax revenue, and population. Their analysis of all public sector trends for the period from 1999 to 2008 showed that changes in population growth had a positive impact on total public expenditure. Similar to Musgrave and Musgrave (1989) and Abeng (2005), they argued that population size is a basic determinant of public expenditure growth. Furthermore, they showed that inflation inversely affected public expenditure: the enormous increase in Nigerian government spending was not evident in the real domestic product, while public debt and tax revenue were positively associated with Nigerian public expenditure. Generally speaking, increases in population growth size correlate with expansion of government expenditure. 
Litvack and Oates (1970) contend that local government spending increases with the concentration of population within a locality. Therefore, public services provisioning varies according to a given jurisdictions' population size (Oates, 1988). According to Wildasin (1986), the crowding cost $^{1}$ of jurisdictions is a theoretical measurement of the relationship between high population density and the increase in local public expenditure. Public finance literature examines the extent to which population size and demographic concentration affect the cost of public services at the subnational level. Neither the public finance literature nor the refugee literature, however, has explored unexpected changes in population (i.e., population changes not due to long-term demographic trends) and its effect on government expenditure. Nakamura and Tahira (2008) empirically tested the relationship between public service costs and population distribution in Japanese municipalities. They found that population size and the area's geographic position are major determinants of public service costs. They argued specifically that the agglomeration and growth of Japanese cities decreased the per capita rate of public services.

Ladd (1992) studied the effect of accelerated population growth on the cost of provisioning public services. He argued that population growth increases the cost of public services and the burden on citizens through the imposition of additional fees to finance them (i.e. constructing schools, health care centers, and infrastructure). Population density increases the per capita cost, and hence additional burdens, to governments, and raises public issues such as whether newcomers should pay extra fees to live in a given country.

\section{The fiscal impact of refugees from previous research}

The presence of refugees in host countries has caused a significant debate over its positive and negative economic consequences and the conditions under which refugees have become either a burden or a potential benefit to the host country's economy. Gomez and Christensen (2011) studied the long-term impact of the influx of refugees on neighboring received countries. They argue that refugees require more public services such as education, health services, and infrastructure. Moreover, refugees are considered competitors of local inhabitants for scarce resources such as water, food, and housing. They show how the protracted influx of refugees has a macroeconomic effect on the receiving country's economy due to the expenditure increases needed to provide refugees with assistance. For example, there was a substantial increase of direct and indirect costs in Malawi's public expenditure in 1990 in response to a massive influx of refugees.(Government of Malawi et al., 1990; Gomez \& Christensen, 2011). UNHCR assistance programs were called in to provide support for both refugees and citizens (Gomez \& Christensen, 2011; Zetter, 1995). Bah (2013) also asserts that the departure of refugees from their home country to a receiving state can cause a host government to provide more public services, depleting scarce resources. Refugees can, however, contribute to their host states' economic growth due to their skills and experience or to the flow of international aid.

Camarota and Zeigler (2015) estimated the cost of an influx of Middle Eastern refugees to the United States by measuring refugee resettlement costs, including the expenditures incurred for health care and human services, public education, social agencies and local government, cash assistance, the Supplemental Nutrition Assistance Program (formerly known as food stamps),processing resettlement applications, and their initial settlement needs such as housing, furnishings, medicine, and employment. The researchers found that Middle Eastern refugees produced a significant cost to the United States. In the same vein, the Migration Policy Debates (2015) assessed the impact of the refugees on Europe's public finance and labor markets. They used short-term public expenditure to estimate this effect because European countries are obligated to provide humanitarian assistance and public services to refugees and asylum seekers. According to Simon (1996), the total public expenditure, including all transfer payments and public education costs, is an effective measure for evaluating comprehensively the costs and benefits of immigrants for receiving states

\section{Dataand Methods}

\section{Data and Sample}

This study uses secondary data from the General Budget Department for the years of 2006-2015 for all Jordanian governorates. The sample of the data set consists of 12 governorates $^{2}$, including Amman,

\footnotetext{
${ }^{1}$ Crowding cost: the cost of provisioning public services based on the population size in a given geographic area (Buettner, Schwager, \& Stegarescu, 2004; Wildasin, 1986).

${ }^{2}$ A governorate: a term, translated from non-English speaking administration, which means state, province or colonies (governorate, n.d.). 
The capital, to estimate the effect of Syrian refugees on public expenditure. This study involves all Jordanian governorates rather than just those that contain Syrian refugee camps (Mafraq, Zarqa, and Irbid), due to the mobility of refugees out of the camps and individuals who have absconded from the camps. In fact, $16 \%$ of Syrian refugees lived in refugee camps, and 84\% lived outside of camps in 2013 (Voon, 2015). The study sample equals 12 Governorates * (10 years).Expenditures were inflated according to Jordan's consumer price index (CPI) with 2006 as the base year. Total public expenditure is in Jordan dinars (JOD), which was converted to United States dollars (USD): thus, $\$ 1=0.709$ for $2006-2011$ and $\$ 1=0.71$ for years 2012-2015 due to the dollar's role as an international reserve currency. Numbers were converted from billions to millions to facilitate the handling of large numbers in a statistical test. The variables used in this study are as follows: Total public expenditure is the dependent variable and "are the expenses which government incurs for the maintenance of the government and the society in general" (Okafor \& Eiya, 2011, p. 44; Oriakhi, 2004).

In this study, total public expenditure was functionally split into two variables, current expenditure and capital expenditure. Two primary public sectors, total public educational expenditure and total public health expenditure were used to define the impact of Syrian refugees on social services and facilities, as well as capital and current expenditure. Total educational expenditure involved current and capital spending on educational institutions, education administration, and subsidies to pupils and their households. Total public health expenditure consisted of current and capital expenditure for providing health services, family planning activities, and emergency aid. The independent variables were coded as follows: Refugee adoption (dummy variable); $0=$ before Syrian refugees' adoption and $1=$ after Syrian refugees' adoption. Regions (Dummy Variable); $1=$ North governorates (Irbid, Ajloun, Jerash, Mafraq); 2 = Centered governorates (Balqa, Amman, Zarqa, Madaba); and $3=$ South governorates (Karak, Tafilah, Ma'an, Aqaba).

\section{Methods}

Multiple regression analysis was the primary analytical method used to test the major hypotheses of this study. Multiple regression is a statistical test which produces an equation that represents the impact of two or more independent variables on a single variable (Babbie, 2013; Meter \& Vannatta, 2010). Regression analysis develops an equation to predict the value of some dependent variables for all of the study population. Also, the resulting equation shows the intensity of the relationships among the variables (Mertler \& Vannetta, 2010). The idea behind multiple regression analysis is that it is an extension of simple linear regression to determine the best-fit line through a series of points (Harris, 1998). The prediction of Y (nominal or ordinal) is based on the following equation. $Y=\beta_{0}+\beta_{1} X_{1}+\cdots+\beta_{2} X_{2}+\beta_{k} X_{k}+$ eUsing a regression model with dummy variables as regressors enables us to estimate the impact of receiving refugees and to add the regional focus factor in order to determine the variation of spending on regions that received more refugees. In spite of some caveats of constructing a regression model based on qualitative predictors, this regression model allow us to reduce the size of error through adding regional focus factor and to overcome the lack of data regarding refugees' existence and settlement costs.

\section{Results}

A regression analysis was conducted to predict the impact of refugees' presence on Jordanian public expenditure, current public expenditure, and capital expenditure using pre-post refugees' adoption and regions as predictors. The pre-post indicator variable was set to zero, before adoption of Syrian refugees. The number 1 was assigned for after adoption of Syrian refugees. The region represents the major administrative divisions of the Jordanian governorates $(1=$ Northern regions, $2=$ center regions, $3=$ Southern regions $)$. An examination of the null hypotheses and regression models reveal the following.

$\mathbf{H O}_{1:}$

The presence of Syrian refugees in Jordan has no effect on the total public expenditure in the provision of public services.

A regression analysis was conducted to predict whether the presence of Syrian refugees affected the total public expenditure when referring to the degree of pressure on public services. Evaluation of linearity led to the natural $\log$ transformation of total public expenditure. The regression results indicated an overall model of pre- and postrefugee adoption predicting the effect of Syrian refugees on total public expenditure, $F(3,116)=18.713, R^{2}=$ $0.326, R_{a d j}^{2}=0.309, p<.005$. More specifically, the regression of pre-post adoption and region predictors was significant, $p<.005$. The regression equation of the model is as follows: 


$$
\text { Total public expenditure }=4.731+0.678_{\text {prepost }}+0.405_{\text {centered }}-.399_{\text {south }}
$$

Generally speaking, Jordanian total public expenditure increased due to the presence of the Syrian refugees. The unstandardized coefficients showed that public spending in centered regions increased more than the north region, while south region public spending, which received fewer refugees, decreased. Therefore, this rejects Null Hypothesis 1 that the presence of Syrian refugees in Jordan had no effect on the total public expenditure in the provision of public services. There was a significant relationship between the influx of Syrian refugees and increases in total public expenditure.

Table 1Model Summary of Total Public Expenditure

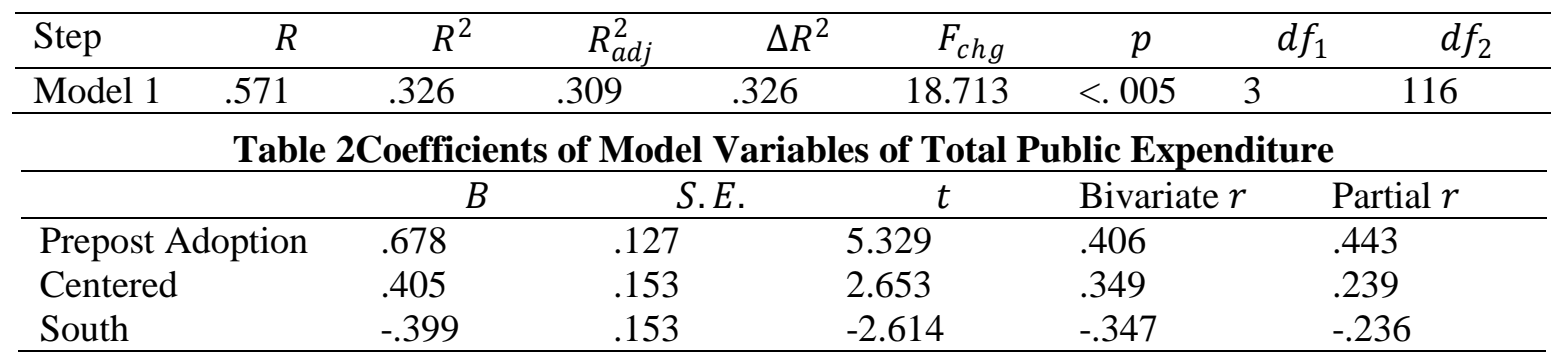

$\mathbf{H O}_{2}$ : The presence of Syrian refugees in Jordan has no effect on current public expenditure in the provision of public services when referring to the functional impact of Syrian refugees on the Jordanian government.

For further investigation, a regression analysis was conducted to look at the abrupt change in the categories of public expenditure to determine the government's priorities in providing public services. Therefore, a regression analysis was conducted to predict the effect of refugees on current public expenditure. Evaluation of linearity led to the natural log transformation of current public expenditure. The regression results indicated that the overall model is significant, $F(3,116)=23.225, R^{2}=0.375$,

$R_{\text {adj }}^{2}=0.359, p<.005$. The regression equation of the model is as follows:

Current public expenditure $=4.358+0.846_{\text {prepost }}+0.370_{\text {centered }}-.721_{\text {so uth }}$

Statistically speaking, Jordanian current public expenditure increased in the presence of Syrian refugees. The unstandardized coefficients indicate that current public spending in centered regions increased more than the north region, while south region public spending, which received fewer refugees, decreased. Therefore, this rejects Null Hypothesis 2 that the presence of Syrian refugees in Jordan had no effect on current public expenditure in the provision of public services when referring to the functional impact of Syrian refugees on the Jordanian government. There was a significant relationship between the influx of Syrian refugees and increases in current public expenditure.

Table 3Model Summary of Current Public Expenditure

\begin{tabular}{|c|c|c|c|c|c|c|c|}
\hline Step & $R$ & $R^{2}$ & $R_{a d j}^{2}$ & $\Delta R^{2}$ & $F_{\text {chg }}$ & $p$ & $d f_{2}$ \\
\hline Model 1 & .613 & .375 & .359 & .375 & 23.225 & $<.005$ & 116 \\
\hline \multicolumn{8}{|c|}{ Table 4Coefficients for Model Variables of Current Public Expenditure } \\
\hline \multicolumn{3}{|r|}{$B$} & \multicolumn{2}{|c|}{ S.E. } & $t$ & Bivariate $r$ & Partial $r$ \\
\hline \multicolumn{2}{|c|}{ Prepost Adoption } & .846 & \multicolumn{2}{|c|}{.150} & 5.635 & .414 & .464 \\
\hline \multicolumn{2}{|c|}{ Centered } & .370 & .18 & & 2.052 & .343 & .187 \\
\hline \multicolumn{2}{|l|}{ South } & -.721 & .18 & & -4.002 & -.426 & -.348 \\
\hline
\end{tabular}

$\mathbf{H 0}_{3:}$ The presence of Syrian refugees in Jordan has no effect on public capital expenditure in the provision of public services when referring to the functional impact of Syrian refugees on the Jordanian government.

A regression analysis was conducted to predict the effect of refugees on capital public expenditure. Evaluation of linearity led to the natural log transformation of capital public expenditure. The regression results indicated that the overall model is significant, $F(3,116)=6.751, R^{2}=0.149, R_{a d j}^{2}=0.127, p<.005$. The regression equation of the model is as follows:

$$
\text { Capitalpublicexpenditure }=3.387+0.324_{\text {prepost }}+0.460_{\text {centered }}+.147_{\text {sout }}
$$

Generally speaking, Jordanian public capital expenditure increased in the presence of Syrian refugees. The unstandardized coefficients illustrate that public spending in centered regions increased more than the north region, similarly south region capital public spending, which received fewer refugees, showed a slight increase. 
Therefore, this rejects Null Hypothesis 3 that the presence of Syrian refugees in Jordan had no effect on capital public expenditure in the provision of public services when referring to the functional impact of Syrian refugees on the Jordanian government. There was a significant relationship between the influx of Syrian refugees and the increase in public capital expenditure.

Table 5Model Summary of Capital Public Expenditure

\begin{tabular}{lrccccccc}
\hline Step & $R$ & $R^{2}$ & $R_{a d j}^{2}$ & $\Delta R^{2}$ & $F_{\text {chg }}$ & $P$ & $d f_{1}$ & $d f_{2}$ \\
\hline Model 1 & .386 & .149 & .127 & .149 & 6.751 & $<.005$ & 3 & 116 \\
\hline
\end{tabular}

Table 6Coefficients for Model Variables of Capital Public Expenditure

\begin{tabular}{lcccll}
\hline & $B$ & $S . E$. & $t$ & Bivariate $r$ & Partial $r$ \\
\hline Prepost Adoption & .324 & .113 & 2.870 & .246 & .257 \\
Centered & .460 & .135 & 3.393 & .282 & .300 \\
South & .147 & .135 & 1.083 & -.061 & .100 \\
\hline
\end{tabular}

$\mathbf{H 0}_{4}$ :The presence of Syrian refugees in Jordan has no impact on the total public educational expenditure when referring to refugees' burden on Jordan as a host country.

A regression analysis was conducted to predict the effect of refugees on total public education expenditure. Evaluation of linearity led to the natural $\log$ transformation of total public-education expenditure. The regression results showed that the model is significant in predicting the effect of refugees on public education expenditure, $F$ $(1,118)=41.147, R^{2}=0.259, R_{a d j}^{2}=0.252$. The regression equation of the model is as follows:

Total public education expenditure $=3.542+0.265$ prepost adoption

For further analysis, a simple linear regression was conducted to look at the unexpected change in the categories of public expenditure to find the Ministry of Education's priorities in providing public schooling services. Therefore, a regression analysis was conducted to predict the effect of refugees on current public-education expenditure. Evaluation of linearity led to the natural log transformation of current public expenditure.

The regression results indicated that the overall model is significant, $F(1,118)=82.383, R^{2}=0.411, R_{\text {adj }}^{2}=$ $0.406, p<.005$. The regression equation of the model is as follows:

Current public education expenditure $=3.296+0.387$ prepost adoption

A regression analysis was conducted to predict the effect of refugees on capital public expenditure. Evaluation of linearity led to the natural log transformation of capital public expenditure. The regression results indicated that the overall model is significant, $F(1,118)=54.753, R^{2}=0.317, R_{a d j}^{2}=0.311, p<.005$. The regression equation of the model is as follows:

Capital public education expenditure $=2.004-0.392_{\text {prepost }}$ adoption

Statistically speaking, Jordanian public-education expenditure increased in the presence of Syrian refugees. Therefore, this rejects Null Hypothesis 4 that the presence of Syrian refugees in Jordan had no impact on total public-educational expenditure when referring to refugees' burden on Jordan as a host country. There was a significant relationship between the influx of Syrian refugees and the increase in public education expenditure.

Table 7Models Summary of the Impact of Syrian Refugees Adoption on Public Education Expenditures

\begin{tabular}{llrccccccc}
\hline & Step & $R$ & $R^{2}$ & $R_{\text {adj }}^{2}$ & $\Delta R^{2}$ & $F_{c h g}$ & $P$ & $d f_{1}$ & $d f_{2}$ \\
\hline Total* & Model 1 & .508 & .259 & .252 & .259 & 41.147 & $<.005$ & 1 & 118 \\
Current & Model 1 & .641 & .411 & .406 & .411 & 82.383 & $<.005$ & 1 & 118 \\
Capital & Model 1 & .563 & .317 & .311 & .317 & 54.753 & $<.005$ & 1 & 118 \\
\hline
\end{tabular}

* Dependent variables

Table 8Coefficients for Final Model of the Impact of Syrian Refugees Adoption on Public Education Expenditures

\begin{tabular}{|c|c|c|c|c|c|c|}
\hline & & $B$ & S.E. & $t$ & Bivariate $r$ & Partial $r$ \\
\hline Total* & Prepost & .265 & .041 & 6.415 & .508 & .508 \\
\hline Current & Prepost & .387 & .043 & 9.076 & .641 & .641 \\
\hline Capital & Prepost & -.392 & .053 & -7.400 & -.563 & -.563 \\
\hline
\end{tabular}

* Dependent variables 
H0 $_{5}$ :The presence of Syrian refugees in Jordan has no impact on the total public health care expenditure when referring to refugees' burden on Jordan as a host country.

A regression analysis was conducted to predict the effect of refugees' adoption on total public-health expenditure. Evaluation of linearity led to the natural log transformation of capital public expenditure. The regression results showed that the overall model is not significant in predicting the effect of refugees' adoption on health care expenditure, $F(1,118)=.518, R^{2}=0.004, R_{a d j}^{2}=-.004$. The regression equation of the model is as follows:

Total public health care expenditure $=4.346+0.087$ prepost adoption

For additional investigation, a regression analysis was conducted to study the abrupt change in the categories of public expenditure to find the government's priorities in providing public health services. Therefore, a regression analysis was conducted to predict the effect of refugees' adoption on current public health care expenditure. Evaluation of linearity led to the natural log transformation of current public expenditure. The regression results indicated that the overall model is significant, $F(1,118)=139.218, R^{2}=0.541, R_{a d j}^{2}=0.537, p<.005$. The regression equation of the model is as follows:

Current public health care expenditure $=3.858+0.511$ prepost adoption

In the same vein, a regression analysis was conducted to predict the effect of refugees' adoption on capital public health care expenditure. Evaluation of linearity led to the natural log transformation of capital public health care expenditure. The regression results indicated that the model is not significant, $F(1,118)=.346, R^{2}=0.003, R_{\text {adj }}^{2}$ $=-0.006, p>.005$. The regression equation of the model is as follows: Capital public health care expenditure $=$ $1.630-0.040$ prepost adoption Generally speaking, Jordanian public health care expenditure increased in the presence of Syrian refugees. Therefore, this rejects Null Hypothesis 5 that the presence of Syrian refugees in Jordan had no impact on the total public health care expenditure when referring to refugees' burden on Jordan as a host country. There was a significant relationship between the influx of Syrian refugees and the increase in public health care expenditure.

Table 9Models Summary of the Impact of Syrian Refugees Adoption on Public Health Expenditures

\begin{tabular}{llrrrrrrrr}
\hline & Step & $R$ & $R^{2}$ & $R_{a d j}^{2}$ & $\Delta R^{2}$ & $F_{c h g}$ & $P$ & $d f_{1}$ & $d f_{2}$ \\
\hline Total* & Model 1 & .066 & .004 & -.004 & .004 & .518 & $>.005$ & 1 & 118 \\
Current & Model 1 & .736 & .541 & .537 & .541 & 139.22 & $<.005$ & 1 & 118 \\
Capital & Model 1 & .054 & .003 & -.006 & .003 & .346 & $>.005$ & 1 & 118 \\
\hline * Dependent variables & & & & & & & &
\end{tabular}

* Dependent variables

Table 10Coefficients for Modelsof the Impact of Syrian Refugees Adoption on Public Health Expenditures

\begin{tabular}{|c|c|c|c|c|c|c|}
\hline & & $B$ & S.E & $t$ & Bivariate $r$ & Partial $r$ \\
\hline Total* & Prepost & .087 & .122 & .720 & .066 & .066 \\
\hline Current & Prepost & .511 & .043 & 11.799 & .736 & .736 \\
\hline Capital & Prepost & -.040 & .068 & -.588 & -.054 & -.054 \\
\hline
\end{tabular}

*Dependent variables

\section{Conclusion}

This study investigated how the presence Syrian refugees has impacted Jordanian public spending at the governorate level. It examined the functional impact of Syrian refugees' presence on current expenditure and capital expenditure. It examined the impact of Syrian refugees on the public spending on health care and education sector at national level. A linear regression analysis has employed to examine how well the predictors explain the differences among the values of dependent variables. On this assumption, the prepost refugee influx and regional divisions of areas of refugee settlement all over Jordan were employed as predictors to determine how the influx of Syrian refugees impacted Jordanian public spending. The empirical analysis results suggest that total public expenditure increased due to the presence of Syrian refugees. Further analysis of the differences between the regions that received more refugees than other regions showed that northern and centered governorates had increased public spending compared to south governorates. The statistical investigation proposed that the current public expenditure increased at the expense of capital spending investment. 
The average increase of the current expenditure was more than the average increase of capital expenditure in northern and centered governorates. We supposed that the additional financial allocations to mitigate the ongoing demand on daily public services through regular current expenditures were replaced with a conservative increase in capital investment. The inferential examination of public education expenditures showed that public education expenditure increased due to the presence of refugees. Ultimately, the statistical analysis examined the impact of the inflow of Syrian refugees on Jordanian health care services. The results suggest that the presence of Syrian refugees positively affected total health care expenditure but negatively affected capital expenditure.

\section{References}

Abeng, M.O. (2005). Determinants of non-debt government expenditure in Nigeria, Bank of Nigeria. Economic Financial Review, 43, 37-71.

Babbie, E. R. (2013). The practice of social research (13th ed.). Belmont, CA: Wadsworth Cengage Learning.

Bah, A. (2013). Civil conflicts as a constraint to regional economic integration in Africa. Defence and Peace Economics, 24(6), 521-534. doi:10.1080/10242694.2012.723155

Buettner, T., Schwager, R., \& Stegarescu, D. (2004). Agglomeration, population size, and the cost of providing public services: An empirical analysis for German states (Discussion paper No. 4, pp. 1-16). Mannheim, Germany: Center for European Economic Research.

Camarota, A. S., \& Zeigler, K. (2015). The high cost of resettling Middle Eastern refugees: Given limited funds, relocation to the U.S. may not be the most effective way to help. New York, NY: Center of Migration Studies.

Francis, A. (2015, September 21). Jordan's refugee crisis. Carnegie Endowment for International Peace, 12. Retrieved from http://carnegieendowment.org/2015/09/21/jordan-s-refugee-crisis-pub-61338

Gomez, M. P., \& Christensen, A. (2011). The impacts of refugees on neighboring countries: A development challenge. The World Development - World Bank.

Government of Malawi, the World Bank, UNDP and UNHCR. (1990). Report to the Consultative Group of Malawi on the impact of refugees on the government public expenditure. Malawi.

Harris, M. B. (1998). Basic statistics for behavioral science research. Boston, MA: Allyn and Bacon.

Jordan General Budget Department. (2017). Jordanian Public Spending FY 2006-2015

Jordan General Budget Department. (2017). Public Education Spending FY 2006-2015

Jordan General Budget Department. (2017). Public Health care Spending FY 2006-2015

Ladd, H. (1992). Population growth, density, and the costs of providing public services. Urban Studies, 29(2), 273-295. doi:10.1080/00420989220080321

Litvack, J. M., \& Oates W. E. (1970). Group size and the output of public goods: Theory and an application to state-local finance in the United States. Public Finance, 25, 42-62.

Mertler, C., \& Vannatta, R. (2010). Advanced and multivariate statistical methods(4th ed.). Glendale, CA: Fred Pyrczak.

Migration Policy Debates. (2015). How will the refugee surge affect the European economy?.Paris, France: The Organization for Economic Co-operation and Development (OECD).

Ministry of Education. (2017). Ministry of Education Syrian refugees' response cost 2013-2015.

Ministry of Education. (2017). Double shifts in public schools percentage.

Ministry of Health, the World Health Organization, the International Advisory, Products and System, the Massachusetts General Hospital Center for Global Health, Harvard University, and the Jordan University for Science and Technology. (2013). Joint Rapid Health Facility Capacity and Utilization Assessment (JRHFCUA).

Ministry of Interior. (2016). Governorates and sectors. Retrieved from http://moi.gov.jo/Pages/viewpage.aspx?pageID=198

MOPIC. (2014, December 17). Jordan response plan 2015 for the Syria crisis. Amman, Jordan: The Ministry of Planning and International Cooperation.

MOPIC. (2015a). Jordan response plan for Syrian crisis 2016-2018. Amman, Jordan: The Ministry of Planning and International Cooperation.

MOPIC. (2015b). Comprehensive vulnerability assessment. Amman, Jordan: The Ministry of Planning and International Cooperation. 
Musgrave, R. A., \& Musgrave, P. B. (1989). Public finance in theory and practice (5th ed.). New York, NY: McGraw-Hill.

Nakamura, K., \& Tahira, M. (2008, April). Distribution of population density and the cost of local public services: The case of Japanese municipalities. University of Toyama.

Nasser, R., \& Symansky, S. (2014, January 5). The fiscal impact of the refugee crisis on Jordan. Washington, DC: The United States Agency for International Development.

Oates, W. E. (1988). On the measurement of congestion in the provision of local public goods. Journal of Urban Economics, 24, 85-94.

Okafor, C., \& Eiya, O. (2011). Determinants of growth in government expenditure: An empirical analysis of Nigeria. Research Journal of Business Management, 5(1), 44-50. doi:10.3923/rjbm.2011.44.50

Oriakhi, D. E. (2004). Introduction to public finance. Benin, Nigeria: Mindex Publishing Co.

Peacock, A. T., \& Wiseman, J. (1961). The growth of public expenditure in the United Kingdom. National Bureau of Economic Research, General Series, No. 72. Princeton, NJ: Princeton University Press.

Peters, G. (1995). The politics of bureaucracy: An introduction to Compare Public Administration. New York, NY: Routledge.

Simon, J. (1996). Public expenditure on immigrants to the United States, past and present. Population and Development Review, 22, 99-109.

The parliament of Jordan. (2017). General information about the National Assembly. Available from: The Parliament of Jordan.

Trading Economics (2017). Jordan government debt to GDP 2007-2015. Retrieved from http://www.tradingeconomics.com/jordan/government-debt-to-gdp

UN High Commissioner for Refugees. (2015). Refugees/migrants emergency response-Mediterranean. Retrieved from http://data.unhcr.org/mediterranean/regional.php

Wagner, A. (1883). Classics in theory of public finance. London, England: Macmillan.

Wildasin, D. (1986). Theoretical analysis of local public economics. In the Handbook of regional and urban economics (Vol. 5, pp. 1131-1178).

Zetter, R. (2015). Are refugees an economic burden or benefit? Refugee Studies Centre, 41, 50-52. 